\title{
Valores priorizados por estudantes universitários de um curso de psicologia de uma universidade pública
}

Nelson Pedro da Silva

\section{Resumo}

A maioria das pesquisas acerca da psicologia da moralidade compartilha a definição de que a moral refere-se a regras e valores cujo propósito é regular as relações interpessoais. No presente estudo, consideramos essa premissa válida porém, também levamos em consideração aspectos relacionados ao Eu. Assim, analisamos os valores priorizados por universitários com a intenção de verificar se esses jovens se pautam por valores públicos, privados e/ou ligados à glória. Os informantes foram 170 estudantes do primeiro ano do curso de psicologia de uma universidade pública localizada na região oeste paulista, de ambos os sexos, com idade média de 20 anos. Para a coleta de dados, aplicamos um questionário contendo perguntas relacionadas aos fatores factuais (idade, sexo e religião) e aos valores prezados pelos universitários. Os resultados - analisados segundo a psicologia das virtudes - mostraram que aproximadamente $70,0 \%$ das respostas válidas emitidas pelos estudantes apontaram a amizade $(32,0 \%)$ e a inteligência $(35,0 \%)$ como os valores mais priorizados. Os valores públicos praticamente não foram mencionados. No tocante às formas de glória, apesar de o percentual não ter sido expressivo para dinheiro e fama, quando os informantes justificaram a opção pela amizade e pela inteligência, conceberam tais valores como meios para a obtenção de dinheiro e fama. Concluímos que esses sujeitos dão pouca importância aos valores relacionados aos deveres (públicos) e a alguma forma de harmonia individual.

\section{Palavras-chave}

Psicologia moral - Valores - Universitários - Ética - Virtudes. 


\title{
Values prioritized by psychology undergraduates of a public university
}

Nelson Pedro da Silva ${ }^{\mathrm{I}}$

\begin{abstract}
Most research on the psychology of morality defines moral as the rules and values whose purpose is to regulate interpersonal relations. In this study, although I have considered such premise valid, I have also taken into account aspects related to the self. Thus, aiming at verifying whether university students are guided by values which are public, private and/or linked to glory, I have analyzed the values prioritized by them. Informants were 170 firstyear psychology undergraduates in a public university located in western São Paulo state, male and female, with an average age of 20 years. To collect the data, I applied a questionnaire concerning factual factors (age, sex and religion) and the values cherished by the undergraduates. The results - analyzed according to the psychology of virtues - have shown that approximately $70 \%$ of the valid answers given by students pointed friendship (32\%) and intelligence (35\%) as the most prioritized values. Public values were hardly mentioned. Concerning the forms of glory, although the percentage for money and fame was not significant, when the informants justified the choice of friendship and intelligence, they conceived such values as a means to obtain money and fame. I have concluded that these individuals give little importance to the values related to duties (which are public) and to some form of individual harmony.
\end{abstract}

\section{Keywords}

Psychology of morality - Values - University students - Ethics - Virtues.

I- Universidade Estadual Paulista UNESP, Assis, São Paulo, Brasil.

Contact: nelsonp1@terra.com.br 


\section{Introdução e justificativas}

Quais são os valores priorizados pelos estudantes universitários de psicologia? Começamos a tecer tal indagação a partir de observações assistemáticas, feitas por nós, a respeito da atual conduta política dos estudantes universitários de um curso de psicologia, matriculados em uma universidade pública localizada na região oeste paulista. Notamos que eles, em sua maioria, abstinham-se da participação política, especialmente da partidária, pois, para eles, além de ser uma prática enfadonha, era sinônimo de corrupção generalizada e algo que não contribuía para a melhoria do status financeiro e social de si mesmos e das pessoas mais próximas.

Outro aspecto referiu-se ao fato de esses sujeitos só se inquietarem com os próprios interesses. A proposta era refletir acerca da própria vida psíquica, com o objetivo de desvelar os verdadeiros sentimentos, não levando em conta o fato de que eles são produzidos socialmente, além de transformarem a convivência com amigos íntimos e familiares em um fim em si mesmo. Senett (1988), a esse propósito, acredita que essa situação está relacionada à valorização da esfera privada em detrimento da pública, o que leva as pessoas, hoje, a não se preocuparem com a descoberta do respeito a princípios supraindividuais.

Carvalho (1989, p. 9) assim resumiu o pensamento acerca do mundo contemporâneo, atravessado pela mentalidade da sobrevivência: "um mundo sem amor, desoxigenante, terminal, incapaz de garantir a socialidade [sic] mínima”.

Segundo Costa $(1988,1989)$ e Lasch (1979, 1986), essa mentalidade é produto de uma cultura de violência que, ao apontar a todo o momento a impotência e a impossibilidade de mudança do sombrio quadro social instituído, ativa mecanismos narcisistas de proteção do Eu.

Esse individualismo - segundo observações assistemáticas - manifesta-se na maioria dos universitários com os quais tivemos contato, por meio das seguintes ações: 1) preferem não assistir às aulas a ter de discordar explicitamente da metodologia empregada pelos docentes e das intervenções feitas por colegas, pois consideram qualquer forma de discussão uma perda de tempo; 2) quando defendem seus pontos de vista, amiúde não chegam sequer a escutar os argumentos apresentados pelos professores e demais colegas; 3) até mesmo quando erram em situações de avaliação, não conseguem ver a incorreção ou interpretam o apontamento do erro como um indicador de perseguição; 4) costumam ver os grandes referenciais teóricos - por exemplo, o marxista, o freudiano e o piagetiano - como sinônimos de sistemas que visam à normatização; e 5) advogam que os únicos fatores merecedores de atenção são a sensibilidade e a própria vida.

Rouanet (1987, p. 124-125) atribui esse movimento a certa leitura de Foucault e aos nouveaux philosophes, pois esses veem:

[...] na razão uma simples protuberância na superfície do poder, encarregada de observar, esquadrinhar, normalizar, e [...] nos inventores de sistemas meros agentes do gulag - os maîtres-penseurs.

Outra explicação para isso, ainda segundo Rouanet (1987), seria uma apologia ao não saber decorrente de uma política sistemática de desvalorização dos conhecimentos humanísticos no Brasil, em nome de uma formação técnica que, atualmente, voltou a ser caminho para a elevação do nível educativo e o consequente desenvolvimento da nação.

Resultado: o conhecimento deixou de ser um valor em si mesmo para os estudantes, a ponto de eles valorizarem unicamente a obtenção de diplomas, ficando o saber renegado a uma posição secundária. A esse respeito, La Taille (2006), ao refletir acerca das relações entre conhecimento e valor, assim se pronunciou:

Tampouco o conhecimento parece ser considerado hoje como riqueza cuja posse, por si só, seria valorizada. Quantos alunos não perguntam: "para que me serve isso?". Ora, boa parte do conhecimento, notadamente científico, responde a uma 
curiosidade pura, não a uma demanda pragmática e urgente (pensemos na Astronomia). Numa sociedade de busca desesperada de prazer imediato e estonteante, a alegria paciente de conhecer fica em segundo plano, ou simplesmente não existe. (LA TAILLE, 2006, p. 8).

Aliado a tudo isso, observa-se entre os universitários um tipo de interação amorosa que banaliza o vínculo afetivo. Por exemplo, ao invés de estabelecerem relações estáveis - como o namoro -, preferem um tipo de relacionamento efêmero, banal e descompromissado, o ficar (MENEZES; BORSSATO, 2010; PEDRO-SILVA; TONON, 2009; SILVA, 2006).

Sublinhamos que esse tipo de interação não está presente apenas no relacionamento amoroso, permeando também as relações de amizade, de trabalho e a de convivência em geral. A natureza desse tipo de relacionamento pauta-se pela superficialidade e pela brevidade, a ponto de Bauman (2004) defini-la como líquida.

Do ponto de vista filosófico, tal indagação acerca dos valores priorizados pelos universitários se justificou pelo fato de autores contemporâneos, como La Taille (1998), apontarem que as pessoas agem moralmente influenciadas por valores, porém não apenas a justiça, como defende Kohlberg (1992).

Em essência, é essa a opinião: de Gilligan (1982) ao afirmar que os homens são guiados pela ética da justiça e as mulheres pela ética do cuidado; de Flanagan (1991) e de Campbell e Christopher (1996), por considerarem contestável, estreita e demasiadamente limitada a redução da moral à ética da justiça e a um conjunto de deveres e regras legisladoras das relações interpessoais; de Tugendhat (1996), que discorda da fundamentação da moral numa razão pura, livre do mundo empírico e das inclinações; e, finalmente, de Taylor (1989), ao argumentar que a filosofia moral moderna tem a tendência de concentrar-se mais no que é certo fazer do que no [que] é bom ser, "antes na definição do conteúdo da obrigação do que na natureza do bem viver”.
Além de justificativas de ordem filosófica, estudos psicológicos a respeito dos valores são relevantes pelo fato de o homem sempre fazer uma leitura valorativa de si. Logo, a imagem que temos a nosso respeito se constitui num valor a ser mantido, pois é vista como uma imagem positiva de si (PERRON, 1991).

Segundo La Taille (1998, 2000, 2002a, 2002b), tal valor pode ser público, privado ou formas de glória. Os públicos são os valores morais e dizem respeito à dimensão do dever agir. Eles objetivam a harmonia social, como é o caso da justiça, e estão alicerçados no preceito kantiano de agir “apenas segundo uma máxima tal que possa ao mesmo tempo querer que ela se torne lei universal” (KANT, 1960, p. 59).

Quanto aos privados, também conceituados de éticos, fundamentam-se no eudemonismo (ARISTÓTELES, 1996) e buscam igualmente a harmonia ou alguma forma de felicidade (dever ser). Contudo, diferentemente dos morais, o referido esforço é feito em nome da harmonia pessoal. Esse é, a nosso ver, o caso da amizade. Apesar de digna de apreço, tal valor é dispensável para se garantir a harmonia social, muito embora cultivá-la seja uma atitude que possibilita certo grau de felicidade. Informamos, porém, que valores desse tipo só podem ser concebidos como éticos se estiverem submetidos aos públicos (morais), pois, se os colocarmos como determinantes de nossas ações, eles deixam de garantir a harmonia social e, em decorrência, também a pessoal.

Quanto às formas de glória (beleza, força física, status financeiro e social), também as compreendemos como valores, pois são estimadas pelas pessoas e fortes influenciadoras de suas condutas. Todavia, não julgamos tais formas como valores públicos e tampouco privados, já que não garantem a harmonia social e muito menos alguma forma de felicidade. Essas estão mais próximas da busca pelo prazer individual (hedonismo), independentemente das consequências que podem ser geradas.

Ainda mais: a presença de um ou de outro tipo de valor é decisiva nas atitudes 
morais. Caso os valores públicos sejam centrais, a pessoa poderá, por exemplo, sentir vergonha, desonra ou indignidade se for medrosa ou cometer ato desonesto; por outro lado, se forem centrais os valores ligados à glória, é provável que esses sentimentos apareçam quando não se tem a riqueza ou o padrão de beleza almejado.

Movimento semelhante pode ser pensado, ainda, no interior do próprio campo moral: o sujeito pode priorizar alguns valores em detrimento de outros. Assim, é possível uma pessoa associar sua "personalidade [identidade] a alguns traços morais (como coragem e lealdade) e não a outros; ou mais a uns do que a outros" (LA TAILLE, 1998, p. 10). Além disso, a mesma pessoa poderá agregar à sua personalidade mais valores públicos, ou seja, relacionados ao como se deve agir, ou privados, isto é, ligados ao como se deve ser.

Outra constatação que nos levou a propor esta pesquisa refere-se à existência de poucos estudos científicos a respeito dos valores priorizados pelos estudantes universitários. Conforme levantamento bibliográfico feito em 2012 na base de dados eletrônicos Dedalus, da USP, e na biblioteca SciELO, encontramos 282 pesquisas por meio dos unitermos psicologia moral; 17 em psicologia da moralidade humana; e, apesar de mais de 700 menções à palavra virtude, apenas 33 pesquisas referiam-se mais diretamente à psicologia das virtudes.

Os estudos e ensaios encontrados objetivaram analisar, principalmente, os seguintes aspectos: a) as relações entre psicologia moral e educação (NUCCI, 2000; DALBERIO, 2007; CARBONE; MENIN, 2004); b) o desenvolvimento moral (LA TAILLE, 2007; BRANCO, 2006); c) o desenvolvimento moral de mulheres (MONTENEGRO, 2003; TESTONI; TONELLI, 2006); d) a homossexualidade e a moral (LACERDA; PEREIRA; CAMINO, 2002); e) o autorrespeito na escola (SOUZA; PLACCO, 2008); f) o campo da bioética (MARCOLINO; COHEN, 2008); g) a moral e os mass media (SILVA; FONSECA; LOURENÇO, 2002); h) as relações entre cognição, afetividade e moralidade (ARAÚJO, 2000; LA TAILLE, 2002a, 2005); i) a família e a moral (BARBOZA et al., 2009; LONGO, 2007); e j) o sentimento de vergonha e sua relação com a psicologia moral (LA TAILLE, 2002a, 2002b).

Especificamente em relação às virtudes, além dos estudos a respeito da generosidade entre crianças (LA TAILLE, 1998; 2006; TOGNETTA, 2006; DIAS, 2002; LIMA, 2000), encontramos, entre outras, pesquisas que abordaram os seguintes valores: a honestidade (FRELLER, 2001); a tolerância (CARNEIRO, 2006); a solidariedade entre crianças e entre adolescentes (TOGNETTA; ASSIS, 2006; D'AUREA-TARDELI, 2006); a coragem (DIAS, 2002); a polidez (LA TAILLE, 2001); e a fidelidade à palavra empenhada (SILVA, 2002).

Deparamo-nos, ainda, com pesquisas e ensaios cuja intenção foi investigar as virtudes de personagens de contos de fadas (SOUZA, 2007) e a relação entre julgamento moral e certas condutas, como a do uso abusivo de álcool (MARTINS, 2006), a indisciplina (LA TAILLE, 1996) e a autoridade (LA TAILLE, 1999). Igualmente, encontramos estudos acerca do ambiente proporcionado pelas escolas e o tipo de raciocínio moral segundo a ética da justiça e o par heteronomia-autonomia (ARAÚJO, 1993; MENIN, 1985; OLIVEIRA et al., 2005) e, remotamente, a respeito do nível de desenvolvimento moral de adolescentes, conforme o referencial kolhbergiano (BIAGGIO, 1994; BZUNECK, 1975; 1979; FREITAG, 1984).

Quanto às pesquisas relacionadas à adolescência e à moral, encontramos a de Guará (2000) a respeito dos padrões morais de adolescentes autores de infração. A pesquisadora verificou que tais jovens vivem entre duas éticas: a do trabalho e a da criminalidade. Além disso, ela constatou que eles valorizam a família, os pactos de lealdade e a cumplicidade nas ações ligadas à transgressão ou à diversão. Defrontamo-nos também com a investigação de Noguchi (2006) acerca da análise do universo moral de adolescentes internos na Febem - SP (atual Fundação 
Casa). A referida pesquisa evidenciou que essa instituição legitima um tipo de educação heterônoma, ou seja, que não propicia o desenvolvimento moral, além de contribuir para a naturalização de relações autoritárias e violentas. Lemos, ainda, o trabalho de Branco (2006), que versou a respeito das representações de violência em jovens residentes na periferia de São Paulo. A referida autora chegou à conclusão de que as várias ações violentas às quais os jovens são expostos interferem nas suas representações tanto do ponto de vista ético quanto do autoconceito.

Quanto aos valores de estudantes universitários, os estudos mais próximos com que nos deparamos foram os de Bataglia (1996), Menin et al. (2008), Harkot-de-La-Taille e La Taille (2006) e Moreira (2009).

$\mathrm{Na}$ pesquisa desenvolvida por Bataglia (1996), os resultados mais pertinentes à nossa problemática - valores dos universitários - evidenciaram que os referidos estudantes tendiam a colocar a dimensão privada acima da pública. Explicamos: no caso dos estudantes e profissionais de psicologia, o sigilo colocou-se como um imperativo mesmo que a ação dos pacientes fosse produtora de desarmonia social. Nesse sentido, para tais sujeitos, os valores como se deve ser, pelo menos no campo da atuação profissional, estão em posição mais alta dos como se deve agir.

Menin et al. (2008), em estudo feito com universitários a respeito do sistema de cotas na universidade (raciais e sociais), constatou a existência de conflito entre mérito e justiça compensatória, devendo, para a maioria deles, prevalecer o merecimento como forma de ingresso nas universidades públicas. Como argumento, a maior parte desses estudantes apontou valores públicos (justiça e igualdade) e privados (esforço próprio).

Na pesquisa produzida por Harkot-deLa-Taille e La Taille (2006, p. 188) acerca dos valores dos jovens de São Paulo, especificamente quanto ao nosso tema, os referidos autores concluíram que o jovem:
[...] elege a moral como essencial para a sociedade, com particular destaque para a justiça, a honestidade e a humildade [...]. Quanto aos desejos, eles recaem sobre ser tratado de forma justa e viver uma vida que vale a pena ser vivida. Ter filhos e reconhecimento social são vistos como importantes, mas menos do que ter emprego e amigos.

Moreira (2009), ao estudar as representações de adolescentes de nível socioeconômico D, de ambos os sexos, que estavam inseridos em um projeto social, concluiu que eles davam importância a valores como o estudo, a relação familiar, a amizade, a honestidade, a justiça e a preocupação quanto ao futuro da sociedade, ou seja, enfatizavam valores públicos e privados. Percebe-se que, para esses jovens, as opções individuais estavam inspiradas em um projeto no qual o outro tinha o seu lugar.

Essa autora verificou, ainda, que eles sofriam quando deparavam com situações nas quais tais valores não eram priorizados, como a brutal e injusta diferença socioeconômica no Brasil. Por causa disso, estavam interessados em contribuir com a construção e/ou a defesa de valores garantidores da harmonia social, e uma das formas para lutar contra essa situação, na opinião deles, era estudar e participar ativamente da solução dos problemas da sociedade.

Em resumo, os estudos realizados na área da moralidade sugerem os seguintes aspectos: a) a maioria versou sobre a mensuração do nível de desenvolvimento moral segundo o par heteronomia/autonomia formulado por Piaget (1957) e os níveis do referido desenvolvimento, tendo como parâmetro a ética da justiça e a análise de Kohlberg (1992); b) alguns buscaram relacionar a psicologia moral com determinados comportamentos (uso abusivo de álcool e indisciplina, por exemplo); c) no campo da psicologia das virtudes, basicamente foi investigada a generosidade em crianças; d) os poucos estudos feitos com adolescentes evidenciaram que, na época em que foram realizados, esses 
jovens priorizavam valores públicos e privados; e) não encontramos estudos específicos acerca dos valores apreciados pelos universitários, e os poucos desenvolvidos com essa população estimaram valores relacionados à dimensão do dever agir (pública) e do dever ser (privada).

\section{Objetivos}

Dados esses aspectos, analisamos os valores priorizados pelos estudantes universitários matriculados em um curso de psicologia.

Buscamos com essa análise responder às seguintes indagações: 1) quais são os valores e as respectivas justificativas apresentadas pelos universitários de tal curso para que os seus colegas priorizem determinados valores?

2) qual é a natureza dos valores que os universitários de psicologia apreciam, isto é, eles são mais afeitos à esfera privada, à pública ou à da glória?

Com a sua concretização, acreditamos ter: a) subsidiado a discussão acerca dos princípios diretores da moralidade de adolescentes;

b) contribuído para o debate acerca dos valores atualmente considerados pelos jovens brasileiros; c) gerado informes sobre aspectos da moral de universitários;

d) contribuído para o preenchimento da lacuna existente na literatura a respeito da psicologia da moralidade.

\section{Método}

Qualquer pesquisador, ao produzir conhecimento, visa a ampliar o poder de esclarecimento de certo referencial teórico-metodológico. Nesse sentido, o presente estudo objetivou ampliar o poder explicativo da psicologia da moralidade humana sistematizada por La Taille (2000, 2002a, 2007), a saber: quais são os valores priorizados (públicos, privados e ligados à glória) pelos estudantes universitários de um curso de psicologia.

Luna assinala, porém, que é importante que um estudo feito em uma instituição vá:
[...] além da constatação das informações por ele coletadas, que suas conclusões possam superar os limites das condições estudadas; em outras palavras, é preciso que ele possa conferir generalidade aos seus resultados. (1999, p. 74).

Em outros termos, colocam-se dois problemas: a representatividade da amostra e a garantia metodológica da generalidade do presente estudo, já que ele foi feito em uma única instituição e, por isso, trata-se de um estudo de caso (LUNA, 1999; MINAYO, 2010).

Para Punch (1998), Coutinho e Chaves (2002), essa questão não se coloca para esse tipo de abordagem. Entretanto, há outros, como Yin (2005), que afirmam ser possível a sua generalização em alguns estudos desse tipo.

Não vamos nos deter nesse debate, pois julgamo-nos não aptos para isso. Para os nossos propósitos aqui, consideramos que, a despeito de o estudo ter sido feito apenas com sujeitos de uma instituição, estes guardam semelhanças em relação aos demais de universidades públicas do estado de São Paulo (ACI, 2003; COMVEST, 2009) e dos institutos federais de ensino superior (IFES, s.d.).

Assim como os sujeitos questionados, os que frequentam institutos federais de educação superior da área de humanidades apresentam as seguintes características: a) a maioria é do sexo feminino e, na época do ingresso, estava na faixa etária compreendida entre 17 e 20 anos; b) a quase totalidade era de solteiros que não tinham filhos; c) mais de 70\% declararam-se brancos/caucasianos; d) eram provenientes de famílias que moravam no seu respectivo estado; e) um pouco mais da metade cursou o ensino médio em escolas públicas; f) a quase totalidade não exercia atividade remunerada; eram de nível socioeconômico, conforme classificação da Associação Brasileira dos Institutos de Pesquisa de Mercado - Abipeme (2008), das classes A1, A2 e B1, e a maioria dos pais tinha cursado o ensino médio (mães) e o superior completo (pais). 
Nesse sentido, pensamos que os resultados obtidos podem ser generalizados, pelo menos, para os demais estudantes regularmente matriculados em cursos de psicologia de universidades públicas e, quiçá, para os que frequentam outros cursos da área de humanidades.

Os sujeitos da pesquisa foram 170 estudantes universitários, de ambos os sexos, com idade entre 17 e 20 anos, os quais estavam matriculados no primeiro ano do curso de psicologia do campus de uma universidade pública localizada na região oeste paulista.

Escolhemos tais sujeitos por compreender que eles serão os futuros responsáveis pelo comando de instâncias da sociedade civil e política, sobremaneira das ligadas às políticas de saúde mental (MOCHCOVITCH, 1990). Além disso, julgamos importante o oferecimento de tais informações aos centros de ensino superior para o caso de eles, porventura, montarem programas de educação moral, pois, como explicaremos mais adiante, os valores priorizados por esses sujeitos não visam à esfera pública.

Importa salientar que empregamos como ferramenta de coleta de informações um questionário contendo indagações relativas a atributos factuais dos entrevistados (idade, sexo e nível socioeconômico) e aos valores prezados por eles, por meio do exame daquilo que creem ser o mais apreciado pela maioria dos estudantes de seu nível de ensino.

Adotamos esse procedimento em razão das respostas dadas em estudo-piloto desenvolvido em 2011. Percebemos que elas eram visivelmente estereotipadas, ou seja, estavam muito mais calcadas no considerado politicamente correto que fundamentadas no efetivamente pensado. Por exemplo, ao indagarmos sobre o que eles mais valorizavam em si mesmos, respondiam o esperado em relação ao establishment. Já quando se referiam aos demais estudantes, atribuíam mais valores ligados à glória.

Tais resultados levaram-nos a decidir colocá-los na posição de analistas. Pressupomos que, ao ocupar esse lugar, eles emitiriam opiniões a respeito de seus pares e, ao mesmo tempo, falariam de si mesmos. Baseamo-nos no fato de que, quando emitimos parecer a respeito de determinado aspecto da realidade, a leitura é sempre feita, conforme Piaget (1959), a partir das nossas estruturas de assimilação. Afinal, quando compreendemos a realidade, falamos a partir do ponto de vista dela (acomodação) e do nosso (assimilação). Nesse sentido, quando apontamos determinada característica do outro, só assinalamos o que somos capazes de enxergar, exatamente porque é nossa também (e, provavelmente, por julgá-la insuportável, não temos consciência dela). Logo, semelhante à defınição de projeção feita por Freud (apud LAPLANCHE; PONTALIS, 1988), o sujeito tende a apontar em outras pessoas aspectos seus amiúde julgados insuportáveis. Considerando tal reflexão e os objetivos do estudo, inquirimos a respeito do que eles consideravam ser mais valorizado pela maioria dos estudantes de seu nível de ensino, em vez de perguntar-lhes acerca de aspectos priorizados em si mesmos.

Além disso, pedimos aos sujeitos que justificassem a resposta dada. Fizemos isso em virtude de a resposta mostrar-se insuficiente para se compreender o seu sentido, além de considerarmos - assim como Piaget (1959; s.d.) e Carraher (1994) - que as justificativas são mais importantes, pois evidenciam o sentido das respostas.

Procedemos da seguinte forma para a coleta das informações: a) primeiramente, entramos em contato com a direção da instituição a fim de obtermos permissão para a coleta das informações; b) em seguida, também pedimos a autorização dos docentes para aplicarmos o instrumento no horário de sua aula; c) esclarecemos os objetivos do estudo e entregamos aos alunos dispostos a colaborar o termo de consentimento livre e esclarecido e, depois, o questionário; d) na sequência, informamos que os procuraríamos em outro horário a fim de obtermos esclarecimentos no caso de não termos entendido alguma das respostas dadas às indagações abertas; 
e) além disso, ficamos à disposição dos sujeitos para dirimir qualquer dúvida; f) por fim, agradecemos aos sujeitos e, novamente, salientamos que a identificação ficaria sob sigilo.

Quanto à análise das informações, inicialmente, fizemos uma leitura minuciosa das justificativas dadas. Em seguida, criamos categorias que foram submetidas à apreciação de juízes (três especialistas da área que se prontificaram a colaborar com o estudo).

Os resultados dessa tabulação foram, então, analisados segundo a teoria dos valores sistematizada por La Taille (2000, 2002a, 2007).

\section{Análise dos resultados}

Dos 170 universitários indagados acerca do principal aspecto que seus pares valorizavam mais, aproximadamente $70,0 \%$ das respostas válidas apontou a amizade (32,0\%) e a inteligência (35,0\%). Praticamente não foram apontadas respostas referentes a valores relacionados à esfera pública, como justiça, honestidade e generosidade (menos de 3,0\% do total). Quanto às formas de glória, o percentual igualmente não foi significativo: apenas $10,0 \%$ apontaram a beleza, 7,0\% indicaram a fama e $2,0 \%$, a riqueza.

Tabela 1 - Respostas apresentadas pelos participantes acerca dos valores priorizados por seus pares

\begin{tabular}{|c|c|}
\hline Respostas & Resultados $(n=164)$ \\
\hline Beleza & $9,8 \%(n=16)$ \\
\hline Fama & $6,7 \%(n=11)$ \\
\hline Riqueza & $1,8 \%(n=3)$ \\
\hline Justiça & $0,6 \%(n=1)$ \\
\hline Honestidade & $0 \%(n=0)$ \\
\hline Generosidade & $1,8 \%(n=3)$ \\
\hline Amizade & $32,3 \%(n=53)$ \\
\hline Inteligência & $34,8 \%(n=57)$ \\
\hline Sinceridade & $6,1 \%(n=10)$ \\
\hline Dedicação aos estudos & $0 \%(n=0)$ \\
\hline Outras respostas & $6,1 \%(n=10)$ \\
\hline
\end{tabular}

Fonte: Dados da pesquisa

Esses resultados levaram-nos a concluir que os valores públicos (ligados ao dever agir) são os menos valorizados pelos universitários (pelo menos, por aqueles matriculados no referido curso de psicologia).

Contudo, os resultados foram diferentes em relação aos valores ligados à glória. Embora o percentual não tenha sido expressivo para beleza, fama e riqueza, quando os jovens justificaram a opção pela amizade e pela inteligência, evidenciaram que tais valores - a nosso ver, dignos de elogio e ligados à dimensão privada (dever ser) - são concebidos como meios para a obtenção de status social e financeiro.

Tais resultados são contrários aos obtidos por Harkot-de-La-Taille e La Taille (2006) e Moreira (2009). Os estudos desses autores mostraram estudantes preocupados, sobremaneira, com a esfera pública (a honestidade e a justiça) e a esfera privada (ter filhos e amigos). Também se opuseram aos do estudo de Menin et al. (2008), pois, embora este não tivesse a intenção de verificar os valores priorizados pelos universitários, a maioria dos sujeitos contrários ao sistema de cotas na universidade justificou seu posicionamento fundamentando-se em valores como a justiça, a igualdade e o mérito.

Como explicar? Inicialmente, conjeturamos que isso decorreu do fato de os sujeitos inquiridos por eles pertencerem a níveis socioeconômicos diferentes dos pesquisados por nós. Contudo, desconsideramos tal hipótese após verificarmos que os adolescentes pesquisados por Harkot-deLa-Taille e La Taille (2006) pertenciam ao nível A1, A2 ou B1 (semelhantemente aos sujeitos entrevistados por nós) e os de Moreira (2009), ao D (ABIPEME, 2008).

Aventamos a possibilidade de que essa mudança estivesse relacionada à idade. A faixa etária dos sujeitos entrevistados por nós estava entre 17 e 20 anos, enquanto os demais autores investigaram sujeitos entre 16 e 18 anos. Consequentemente, pelo fato de uma parte dos nossos sujeitos serem mais velhos cronologicamente e, possivelmente, terem construído mais experiências, apresentariam uma visão menos "romântica" da sociedade. Apesar de plausível, acabamos por também 
descartar essa hipótese, amparados em uma pesquisa-piloto realizada por nós ao construirmos o método. Nesta, pedimos aos sujeitos que apontassem os valores preferidos por eles. 0 resultado foi praticamente o mesmo do encontrado nos estudos citados. Nesse sentido, julgamos pouco provável a idade ter influenciado nas respostas a ponto de nossos sujeitos terem emitido opiniões diferentes das verificadas na literatura.

Chegamos, então, a considerar que tais diferenças estavam relacionadas ao clima cultural geral, isto é, “a influência ideológica pela qual os media modelam a opinião pública” (ROUANET, 1987, p. 175). Todavia, desconsideramos de imediato essa hipótese, pois, apesar de os estudos terem sido desenvolvidos em épocas diferentes (o nosso, em 2012; o de Harkot-de-La-Taille e La Taille, em 2006; o de Menin, em 2008; e o de Moreira, em 2009), o referido clima de apologia ao narcisismo, ao consumismo e ao higienismo, em detrimento dos valores afeitos à harmonia social, praticamente manteve-se inalterado.

Diante do exposto, consideramos que tais resultados foram diferentes por causa da maneira como as indagações foram feitas. Explicamos: os sujeitos pesquisados por tais autores foram questionados sobre os valores prezados, enquanto nós os indagamos acerca do que consideravam prioridade para seus pares. Essa mudança metodológica, a nosso ver, fez toda a diferença, pois, ao colocarmos os respondentes na posição de informantes, pudemos obter dados a respeito do que acreditavam serem os valores priorizados por seus pares e, indiretamente, por eles próprios. Isso evidenciou que formas de glória continuam a ser os elementos mais influenciadores, ao menos, de seus juízos.

Ainda com a finalidade de corroborarmos nossa hipótese, relacionamos a seguir as justificativas apresentadas pelos sujeitos para considerarem que a amizade, um valor privado, atende a interesses de glória.
Tabela 2 - Justificativas apresentadas pelos participantes para que os estudantes universitários de psicologia considerem a amizade um dos valores priorizados por seus pares

\begin{tabular}{c|c}
\hline Justificativas & Resultados ( $n=60)$ \\
\hline $\begin{array}{c}\text { Auxilia na adaptação a uma nova realidade } \\
\text { distante dos familiares }\end{array}$ & $41,7 \%(\mathrm{n}=25)$ \\
\hline $\begin{array}{c}\text { Possibilita obter ajuda (sobretudo de natureza } \\
\text { escolar) }\end{array}$ & $21,7 \%(\mathrm{n}=13)$ \\
\hline $\begin{array}{c}\text { Facilita a convivência no meio estudantil } \\
\text { É o principal tipo de relação que se estabelece } \\
\text { na universidade }\end{array}$ & $16,7 \%(\mathrm{n}=10)$ \\
\hline $\begin{array}{c}\text { É na época da faculdade que se formam as } \\
\text { amizades sólidas }\end{array}$ & $5,0 \%(\mathrm{n}=3)$ \\
\hline Propicia status no meio acadêmico & $5,0 \%(\mathrm{n}=3)$ \\
\hline Possibilita obter ajuda profissional futura & $3,3 \%(\mathrm{n}=2)$ \\
\hline Outras justificativas & $3,3 \%(\mathrm{n}=2)$ \\
\hline
\end{tabular}

Fonte: Dados da pesquisa

Como se pode observar na tabela 2, das 60 justificativas válidas apresentadas pelos 53 participantes que apontaram a amizade como o valor mais considerado por seus pares, em torno de 40,0\% indicou como motivo o fato de ela propiciar a adaptação a uma nova realidade distante dos familiares e, em decorrência, por meio dela, ter algum tipo de acolhimento e de combate à solidão.

Esses resultados sugerem que a amizade tem uma função pragmática para tais sujeitos, isto é, possibilita atingir objetivos práticos.

Essa visão, a nosso ver instrumental, indica que os amigos não são vistos como fins em si mesmos, mas como meio (objeto) para se obter algo: no caso em questão, a substituição dos pais e os benefícios pressupostos de uma relação filial.

Tal concepção levou-nos a refletir acerca do significado da amizade. Parece-nos que, em todas as relações igualitárias, inclusive nessa, as condições essenciais são o respeito mútuo e o medo - todo moral - de decair perante o olhar do sujeito respeitado, tese levantada por Piaget (1957) e objeto de estudo sistemático de La Taille (2002a; 2002b), o qual este último autor denominou de sentimento de vergonha. 
Assim, em relações fundamentadas no respeito mútuo, como a de amizade, segundo Piaget (1957), os envolvidos buscariam agir levando em consideração o outro, ou seja, de maneira recíproca. E isso não somente porque esse respeito demanda tal ação, mas principalmente pelo receio - todo moral - de decair perante o olhar da pessoa respeitada.

Acontece que a amizade concebida de maneira pragmática prescinde desse medo, pois não há interação. Ao contrário, vive-se ao lado de outras pessoas. Isso mostra que pouca ou nenhuma importância é dada ao olhar alheio até mesmo do suposto amigo.

Como no presente estudo o objetivo não é refletirmos longamente sobre a amizade, mas analisarmos os motivos pelos quais os estudantes a apresentaram como um dos valores priorizados por seus pares, basta-nos afirmar que, para os universitários entrevistados, a amizade é estabelecida por interesse.

Mesmo assim, poderíamos tecer a seguinte indagação: ao agirem assim, esses jovens não estariam sendo movidos por alguma ética, como a utilitarista? Não cremos. Diríamos que se trata de um arremedo malfeito de tal conjunto de princípios.

Explicamos: para essa ética: “as ações são boas quando tendem a promover a felicidade; más quando tendem a promover o oposto da felicidade". Por conseguinte, as ações, boas ou más, são assim consideradas desde a visão de "suas consequências, sendo o objetivo de uma boa ação, [...] promover em maior grau o bem geral" (JAPIASSU; MARCONDES, 1989, p. 240, grifos nossos). Concluímos, então, que os sujeitos questionados não foram movidos por essa doutrina, pois faltou a reflexão a respeito do bem geral. Basicamente, eles estavam preocupados consigo mesmos.

Por isso, levantamos a hipótese de que esses jovens não concebem a amizade como uma virtude, mas como uma forma de glória, uma espécie de narcisismo, em que o outro é visto apenas como objeto para a satisfação ou preenchimento das próprias faltas.
Vejamos, agora, as justificativas apresentadas para a inteligência.

Como se pode ver na tabela 3, mais de $40,0 \%$ das justificativas dadas pelos sujeitos apontaram a inteligência como o aspecto mais valorizado por seus pares. Os argumentos principais foram: ela possibilita a aquisição de status social no meio acadêmico e fora dele (cerca de 50,0\% das justificativas) e ela viabilizou o ingresso em uma universidade pública (20,0\%).

Tabela 3 - Justificativas apresentadas pelos participantes para que os estudantes universitários de psicologia considerem a inteligência um dos valores priorizados por seus pares.

\begin{tabular}{c|c}
\hline Justificativas & $\begin{array}{c}\text { Resultados } \\
(\mathrm{n}=68)\end{array}$ \\
\hline $\begin{array}{c}\text { Possibilita a aquisição de status social na } \\
\text { sociedade }\end{array}$ & $17,6 \%(\mathrm{n}=12)$ \\
\hline $\begin{array}{c}\text { Propicia obter status social no meio acadêmico } \\
\text { Viabiliza o ingresso em uma universidade, } \\
\text { principalmente a pública }\end{array}$ & $17,6 \%(\mathrm{n}=12)$ \\
\hline $\begin{array}{c}\text { Permite o desenvolvimento intra e interpessoal } \\
\text { cossibilita a aquisição de determinados }\end{array}$ & $13,2 \%(\mathrm{n}=9)$ \\
\hline $\begin{array}{c}\text { Consideram-se superiores aos que não } \\
\text { sociedade }\end{array}$ & $10,3 \%(\mathrm{n}=7)$ \\
\hline $\begin{array}{c}\text { conseguiram ingressar na universidade, } \\
\text { sobretudo na pública }\end{array}$ & $4,4 \%(\mathrm{n}=3)$ \\
\hline $\begin{array}{c}\text { Propicia o diálogo e o debate no meio acadêmico } \\
\text { É um atributo estimulado e valorizado na } \\
\text { universidade }\end{array}$ & $4,4 \%(\mathrm{n}=3)$ \\
\hline \begin{tabular}{c} 
Outras justificativas \\
\hline
\end{tabular} & $2,9 \%(\mathrm{n}=2)$ \\
\hline
\end{tabular}

Fonte: Dados da pesquisa

A primeira indagação a ser tecida antes da análise desses resultados é: afinal, o que significa a inteligência? Não será o homem ignorante do saber sistematizado uma pessoa inteligente? 0 fato de pensarmos não é indicador de que somos inteligentes?

Ser inteligente, para Piaget (1983), significa fazer uso de instrumentos com a finalidade de resolver um dado problema. Para o autor, a inteligência é definida como a "solução de um problema novo para o indivíduo, é a coordenação dos meios para atingir certo 
fim, que não é acessível de maneira imediata" (PIAGET, 1983, p. 216).

Nesse sentido, o indivíduo ignorante do saber acadêmico também é inteligente, pois faz uso de seus conhecimentos para transpor os obstáculos que impedem sua adaptação à realidade. Disso se conclui que ser inteligente não significa, necessariamente, ter ingressado em estabelecimentos de ensino superior. A pessoa ignorante do saber acadêmico pode ter malogrado no seu intento por não ter os conhecimentos exigidos para ser aprovada em um exame vestibular ou até mesmo por falta de condições financeiras para fazê-lo ou de vontade. Gramsci (1968) foi exemplar ao dizer que todos os seres humanos são filósofos; logo, inteligentes (afinal, todos pensam).

Tais observações levam-nos à terceira interrogação: o pensar não é indicador de inteligência? Acreditamos que sim. Por esse motivo, fomos levados a indagar alguns dos participantes acerca de seu entendimento do que é ser inteligente. Em um primeiro momento, eles se sentiram embaraçados para nos responder. Entretanto, com base nas respostas dadas, concluímos que, para esses jovens, inteligência é sinônimo de ter os conhecimentos valorizados acadêmica e socialmente e/ou que são requisitos para o ingresso em uma universidade.

Por esse motivo, tomamos - no presente estudo - a expressão ser inteligente como sinônimo de aquisição de determinados saberes sistematizados e amiúde valorizados acadêmica e socialmente.

La Taille (1999; 2005), ao dissertar acerca da relação entre conhecimento e valor, afirma que o primeiro pode ser visto de quatro maneiras: a) meio para a aquisição de riqueza cultural desinteressada (portanto, um fim em si mesmo); b) fator que contribui para o progresso da humanidade; c) igualmente, aspecto que pode possibilitar a obtenção de status social; d) por fim, instrumento que favorece a construção da autonomia e, consequentemente, protege-nos da alienação a que somos constantemente submetidos.
Notamos, pelas justificativas oferecidas (tabela 3), que o saber é visto como forma de os sujeitos conseguirem status acadêmico e social. Afınal, para tais estudantes, conforme a avaliação de seus pares, ele possibilitou o ingresso em uma universidade pública e/ou a aquisição de prestígio no meio acadêmico e fora dele.

Já o conhecimento sistematizado não foi apontado como meio para auxiliar no progresso da sociedade. Semelhantemente ao que foi apontado no estudo de Bataglia (1996), os estudantes parecem não se importar com tal aspecto.

Poderíamos dizer que o conhecimento é visto como fator de desalienação e busca desinteressada pelo saber, pois $25,0 \%$ das justificativas remetem ao desenvolvimento pessoal. Contudo, julgamos prematuro fazer tal afırmação, pois o conteúdo das justificativas não nos permite emitir esse tipo de parecer. Tendemos a considerar que - assim como a maioria dos motivos - o interesse pelo conhecimento, nesses casos, visa ao prestígio pessoal.

\section{Conclusões e considerações finais}

A respeito dos universitários investigados, concluímos:

1. Para esses estudantes, seus pares pouco priorizam valores públicos, isto é, afeitos ao dever agir (moral);

2. Igualmente, têm pouco apreço pelos valores privados, ou seja, atinentes à harmonia individual ou pela efetivação de alguma forma de felicidade (dever ser);

3. Apesar de apontar valores considerados em si dignos de elogio, como a inteligência e a amizade, concebem tais excelências como meio para obtenção de status social e riqueza;

4. Apresentam-se como defensores de um arremedo da ética utilitarista, pois se guiam apenas pela busca da satisfação do próprio bem.

Entendemos que tal estudo deve ser feito com outros estudantes de psicologia tanto de faculdades públicas quanto privadas. Defendemos tal sugestão pelo fato de a maioria dos entrevistados apresentarem determinada 
peculiaridade: eles provêm de cidades localizadas a mais de duzentos quilômetros daquela onde está localizada sua universidade. Diante disso, indagamos: será que os matriculados em uma faculdade na mesma cidade, onde residem, apontariam a amizade como valor priorizado por seus pares? Não seria a prioridade dada à amizade muito mais um fator conjuntural?

Julgamos necessárias, igualmente, a realização de investigações com universitários de outros cursos e a análise da distribuição das respostas e das justificativas em função de fatores factuais (sexo, idade, nível socioeconômico, tipo de estabelecimento de ensino frequentado, religião, etnia, entre outras variáveis).

Outro aspecto refere-se à influência do curso tanto na manutenção quanto na mudança dos valores e das justificativas apresentadas. Dessa forma, consideramos necessária a realização de estudos que busquem comparar alunos matriculados nos primeiros e últimos anos do curso de psicologia. Questionamos: o referido curso universitário influencia nos valores e nas justificativas apresentadas pelos estudantes acerca de seus pares?

Informamos, por fim, que estamos dando prosseguimento ao presente estudo, analisando questões referentes: a) ao que tais sujeitos fariam se tivessem recursos financeiros para mudar a realidade; b) aos valores que eles gostariam de ver em seus filhos; c) ao que mudariam neles próprios; d) àquilo de que têm mais medo; e e) a aspectos que julgam necessários para serem felizes.

\section{Referências}

ABIPEME - Associação Brasileira dos Institutos de Pesquisa de Mercado. Proposição para um novo critério de classificação socioeconômica. São Paulo, 2008. Mimeografada.

ACl - Assessoria de Comunicação e Imprensa. Jornal da UNESP. Disponível em: <http://www.unesp.br/aci/jornal/180/>. Acesso em: 2 abr. 2014.

ARAÚJO, Ulisses Ferreira de. Um estudo da relação entre "ambiente cooperativo" e julgamento moral na criança. Campinas, 1993. 208 f. Dissertação (Mestrado em Psicologia da Educação) - Faculdade de Educação, Universidade de Campinas, 1993.

ARAÚJO, Valéria Amorim Arantes de. Cognição, afetividade e moralidade. Educação e Pesquisa, São Paulo, v. 26, n. 2, p. 137153, jul./dez, 2000.

ARISTÓTELES (343 a.C.). Ética a Nicômaco. São Paulo: Nova Cultural, 1996. p. 118-320. (Os pensadores).

BARBOZA, Ana Lúcia Alves et al. Mães de sonhos: uma proposta de reflexão e intervenção nas relações familiares. Saúde e Sociedade, São Paulo, v. 18, n. 1, p. 57-62, mar. 2009.

BATAGLIA, Patricia Unger Raphael. Estudo sobre o juízo moral e a questão ética na prática da psicologia. São Paulo, 1996. 209 f. (+ anexos). Dissertação (Mestrado em Psicologia) - Instituto de Psicologia, Universidade de São Paulo, 1996.

BAUMAN, Zygmunt. Amor líquido: sobre a fragilidade dos laços humanos. Rio de Janeiro: Zorge Zahar, 2004.

BIAGGI0, Angela Maria Brasil; KEUNECKE, Cristina M; BARDAGI, Marucia. Desenvolvimento moral em estudantes de ciências jurídicas e juízes de direito. Psicologia: Reflexão e Crítica, v. 7, n. 1, p. 15-28, 1994. 
BRANCO, Thais Helena Cardinale. Relação entre condições de vida e representação da violência em jovens residentes em bairro da periferia de São Paulo. São Paulo, 2006. Dissertação (Mestrado em Psicologia Escolar e do Desenvolvimento Humano) - Universidade de São Paulo, 2006.

BZUNECK, José Aloyseo. Desenvolvimento moral: avaliação dos estágios kohlbergianos em crianças e adolescentes de Londrina. São Paulo, 1975. 92 f. Dissertação (Mestrado em Psicologia) - Instituto de Psicologia, Universidade de São Paulo, 1975.

BZUNECK, José Aloyseo. Julgamento moral de delinquentes e não delinquentes em relação à ausência paterna. São Paulo, 1979. 184 f. Tese (Doutorado em Psicologia) - Instituto de Psicologia, Universidade de São Paulo, 1979.

CAMPBELL, Robert; CRISTOPHER, John Chambers Christopher. Moral development theory: a critique of its kantian presuppositions. Developmental Review, v. 16, n. 1, p. 1-47, 1996

CARBONE, Renata Aparecida; MENIN, Maria Susana de Stéfano. Injustiça na escola: representações sociais de alunos do ensino fundamental e médio. Educação e Pesquisa, São Paulo, v. 30, n. 2, p. 251-270, maio/ago. 2004.

CARNEIRO, Maria Luiza Tucci. A tolerância como virtude. Revista USP, v. 69, p. 6-13, 2006.

CARVALHO, Eduardo de A. [Prefácio]. In: COSTA, Jurandir Freire. Psicanálise e moral. São Paulo: Educ, 1989. p. 8-9.

COMVEST - Comissão Permanente para os Vestibulares - UNICAMP. Perfil socioeconômico dos inscritos e matriculados -Vestibular Unicamp 2009. Disponível em: <http://www.comvest.unicamp.br/estatisticas/perfi//perfil2009.pdf>. Acesso em 3 abr. 2014.

CARRAHER, Terezinha Nunes. 0 método clínico: usando os exames de Piaget. São Paulo: Cortez, 1994.

COSTA, Jurandir Freire. Narcisismo em tempos sombrios. In: BIRMAN, Joel (Coord.). Percursos na história da psicanálise. Rio de Janeiro: Taurus, 1988. p. 151-174.

COSTA, Jurandir Freire. Psicanálise e moral. São Paulo: Educ, 1989.

COUTINHO, Clara Pereira; CHAVES, José Henrique. 0 estudo de caso na investigação em tecnologia educativa em Portugal. Revista Portuguesa de Educação, v. 15, n. 1, p. 221-244, 2002.

D'AUREA-TARDELI, Denise. A manifestação da solidariedade em adolescentes: um estudo sobre a personalidade moral. São Paulo, 2006. 254 f. Tese (Doutorado em Psicologia Escolar e do Desenvolvimento Humano) - Instituto de Psicologia, Universidade de São Paulo, 2006.

DALBERIO, Osvaldo. Perspectivas éticas para a educação: uma reflexão sobre seus pressupostos humanísticos. Educere, Venezuela, v. 11, n. 37, p. 241-245, abr./jun. 2007.

DIAS, Andrea Cristina Felix. Estudo psicológico sobre o lugar das virtudes no universo moral aos 7 anos de idade. São Paulo, 2002. 156 f. Dissertação (Mestrado em Psicologia Escolar e do Desenvolvimento Humano) - Instituto de Psicologia, Universidade de São Paulo, 2002.

FLANAGAN, Owen. Psychologie morale et éthique. Paris: Puf, 1991. p. 213-237.

FREITAG, Bárbara. Sociedade e consciência: um estudo piagetiano na favela e na escola. São Paulo: Cortez: Autores Associados, 1984.

FRELLER, Cintia Copit. Moralidade, ética e inclusão escolar: furtos na escola. Estilos da Clínica, v. 6, n. 11, p. 33-46, dez. 2001.

IFES. Instituições Federais de Ensino Superior. Pesquisa do perfil socioeconômico e cultural do estudante de graduação das IFES brasileiras. Disponível em: <http://www.unb.br/administracao/decanatos/dac/fonaprace/perfil/perfil.html>. Acesso em: 4 abr. 2014.

GILLIGAN, Carol. In a different voice: psychological theory and wome's development. Cambridge: Harvard University Press, 1982. GRAMSCI, Antônio. Os intelectuais e a organização da cultura. Rio de Janeiro: Civilização Brasileira, 1968.

GUARÁ, Isa Maria Ferreira da Rosa. 0 crime não compensa, mas não admite falhas: padrões morais dos jovens autores de infração. São Paulo, 2000. 187 f. Tese (Doutorado em Serviço Social) - Faculdade de Serviço Social, Pontifícia Universidade Católica, 2000. 
HARKOT-DE-LA-TAILLE, Elizabeth; LA TAILLE, Yves. de. Valores dos jovens de São Paulo. In: LA TAILLE, Yves de. Moral e ética: dimensões intelectuais e afetivas. Porto Alegre: Artmed, 2006. p. 151-189.

JAPIASSU, Hilton; MARCONDES, Danilo. Dicionário básico de filosofia. Rio de Janeiro: Jorge Zahar, 1989.

KANT, Immanuel. Fundamentação da metafísica dos costumes. Lisboa: Edições 70, 1960.

KOHLBERG, Lawrence. Psicología del desarrollo moral. Bilbao: De. Desclée, 1992. p. 33-40.

LA TAILLE, Yves de. A indisciplina e o sentimento de vergonha. In: AQUINO, Julio Groppa. Indisciplina na escola: alternativas teóricas e práticas. São Paulo: Summus, 1996. p. 9-23.

LA TAILLE, Yves de. Para um estudo psicológico da honra. In: BANKS LEITE, Luci (Org.). Percursos piagetianos. São Paulo: Cortez, 1997. p. 225-241.

LA TAlLLE, Yves de. As virtudes morais segundo as crianças. São Paulo: Instituto de Psicologia, 1998. Mimeografada.

LA TAILLE, Yves de. Autoridade na escola. In: AQUINO, Julio Groppa. Autoridade e autonomia na escola: alternativas teóricas e práticas. São Paulo: Summus, 1999. p. 9-29.

LA TAlLLE, Yves de. Para um estudo psicológico das virtudes. Educação e Pesquisa, São Paulo, v. 26, n. 2, p. 109-121, jul./dez. 2000.

LA TALLLE, Yves de. Desenvolvimento moral: a polidez segundo as crianças. Cadernos de Pesquisa, São Paulo, n. 114, p. 89-119, nov. 2001.

LA TAILLE, Yves de. Vergonha, a ferida moral. Petrópolis: Vozes, 2002a.

LA TAILLE, Yves de. 0 sentimento de vergonha e suas relações com a moralidade. Psicologia: Reflexão e Crítica, Porto Alegre, v. 15, n. 1, p. 13-25, 2002b.

LA TAILLE, Yves de. A escola e os valores: a ação do professor. In: LA TAILLE, Yves de; JUSTO, José Sterza; PEDRO-SILVA, Nelson. Indisciplina/disciplina. Porto Alegre: Mediação, 2005. p. 5-21.

LA TAILLE, Yes de. A importância da generosidade no início da gênese da moralidade na criança. Psicologia: Reflexão e Crítica, Porto Alegre, v. 19, n. 1, 2006.

LA TAILLE, Yves de. Desenvolvimento humano: contribuição da psicologia moral. Psicologia USP, São Paulo, v. 18, n. 1, p. 11-36, 2007.

LACERDA, Marcos; PEREIRA, Cícero; CAMINO, Leoncio. Um estudo sobre as formas de preconceito contra homossexuais na perspectiva das representações sociais. Psicologia: Reflexão e Crítica, Porto Alegre, v. 15, n. 1, p. 165-178, 2002.

LAPLANCHE, Jean; PONTALIS, Jean-Bertrand. Vocabulário da psicanálise. São Paulo: Martins Fontes, 1988.

LASCH, Christopher. The culture of narcissism: American life in an age of diminishing expectations. New York: Warner Books, 1979.

LASCH, Christopher. 0 mínimo eu: sobrevivência psíquica em tempos difíceis. São Paulo: Brasiliense, 1986.

LIMA, Vanessa Aparecida Alves de. A generosidade segundo sujeitos de 6, 9 e 12 anos. São Paulo, 2000. 153 f. Dissertação (Mestrado em Psicologia Escolar e do Desenvolvimento Humano) - Instituto de Psicologia, Universidade de São Paulo, 2000.

LONGO, Cristiano da Silveira. Violência doméstica contra crianças e adolescentes (VDCA) e educação da afetividade e da moralidade: expressões de sentidos da palmada na linguagem de desenhos infantis. São Paulo, 2007. 618 f. Tese (Doutorado em Psicologia) - Instituto de Psicologia, Universidade de São Paulo, 2007.

LUNA, Sergio Vasconcelos de. Planejamento em pesquisa: uma introdução. São Paulo: Educ, 1999.

MARCOLINO, José Álvaro; COHEN, Claudio. Sobre a correlação entre a bioética e a psicologia médica. Revista Associação Médica Brasileira, v. 54, n. 4, p. 363-368, 2008. 
MARTINS, Raul Aragão. Uso de álcool, intervenção breve e julgamento sociomoral em adolescentes que bebem excessivamente. São José do Rio Preto, 2006. 211 f. Tese (Livre-Docência em Psicologia da Educação) - Instituto de Biociências, Letras e Ciências Exatas, Universidade Estadual Paulista, 2006.

MENEZES, Honório Sampaio; BORSSATO, Fabiane. Comportamento afetivo de universitários de uma instituição privada. Revista da AMRIGS, Porto Alegre, v. 54, n. 1, p. 49-58, jan./mar. 2010.

MENIN, Maria Suzana de Stefano. Autonomia e heteronomia às regras escolares: observações e entrevistas na escola. São Paulo, 1985. 215 f. Dissertação (Mestrado em Psicologia Escolar e do Desenvolvimento Humano) - Instituto de Psicologia, Universidade de São Paulo, 1985.

MENIN, Maria Suzana de Stefano. et al. Representações de estudantes universitários sobre alunos cotistas: confronto de valores. Educação e Pesquisa, São Paulo, v. 34, n. 2, p. 255-272, maio/ago. 2008.

MINAYO, Maria Cecília de Souza (Org.). Pesquisa social: teoria, método e criatividade. Petrópolis: Vozes, 2010.

MOCHCOVITCH, Luna Galano. Gramsci e a escola. São Paulo: Ática, 1990.

MONTENEGRO, Thereza. Diferenças de gênero e desenvolvimento moral das mulheres. Revista Estudos Feministas, Florianópolis, v. 11, n. 2, p. 493-508, jul./dez. 2003.

MOREIRA, Francy Ribeiro. Adolescentes: (des)amparo e vida psíquica. Assis, 2009. 140 f. Dissertação (Mestrado em Psicologia) Faculdade de Ciências e Letras, Universidade Estadual Paulista, 2009.

NOGUCHI, Natália Félix de Carvalho. Seguro na Febem - SP: universo moral e relações de poder entre adolescentes internos. São Paulo, 2006. 176 f. Dissertação (Mestrado em Psicologia Escolar e do Desenvolvimento Humano) - Instituto de Psicologia, Universidade de São Paulo, 2006.

NUCCl, Larry. Psicologia moral e educação: para além de crianças "boazinhas”. Educação e Pesquisa, São Paulo, v. 26, n. 2, jul./dez. 2000.

OLIVEIRA, Fábia Sampaio de et al. Ideais e identificações em adolescentes de Bom Retiro. Psicologia e Sociedade, Porto Alegre, v. 17, n.3, set./dez. 2005.

PEDRO-SILVA, Nelson; TONON, Fábio. Uma análise piagetiana dos relacionamentos amorosos na adolescência: resultados preliminares. In: COLÓQUIO INTERNACIONAL DE PSICOLOGIA E EPISTEMOLOGA GENÉTICA: ATUALIDADE DA OBRA DE JEAN PIAGET, 1. Anais... Marilia: Unesp, 2009, p. 583-586.

PERRON, Roger. Les représentations de soi. Toulouse: Privat, 1991.

PIAGET, Jean. A representação do mundo na criança. Rio de Janeiro: Record, [19--]. p. 5-28.

PIAGET, Jean. Étude d'épistemologie génétique. Paris: PUF, 1959.

PIAGET, Jean. Le jugement moral chez l'enfant. Paris: PUF, 1957.

PIAGET Jean. 0 tempo e o desenvolvimento intelectual da criança. In: PIAGET, Jean. A epistemologia genética: sabedoria e ilusões da filosofia; problemas de psicologia genética. São Paulo: Abril Cultural, 1983 (Os pensadores). p. 209-225.

PUNCH, Keith. Introduction to social research: quantitative \& qualitative approaches. London: Sage, 1998.

ROUANET, Sergio Paulo. Teoria crítica e psicanálise. Rio de Janeiro: Tempo Brasileiro, 1987.

SENETT, R. 0 declínio do homem público. São Paulo: Companhia das Letras, 1988.

SILVA, Nelson Pedro da. Entre o público e o privado: um estudo sobre a fidelidade à palavra empenhada. São Paulo, 2002. 353

f. Tese (Doutorado em Psicologia Escolar) - Instituto de Psicologia, Universidade de São Paulo, 2002. 
SILVA, Ailton Amélio da. 0 conteúdo da vida amorosa de estudantes universitários. Interação em Psicologia, Curitiba, v. 10, n. 2 , p. 301-312, jul./dez. 2006.

SILVA, Cristina; FONSECA, Estela; LOURENÇO, Orlando. Valores morais em televisão: análise de uma série televisiva de grande audiência. Análise Psicológica, Lisboa, v. 4, n. 20, p. 541-553, 2002.

SOUZA, Maria Thereza Costa Coelho. As virtudes nos contos de fadas: considerações a partir da teoria de Jean Piaget. In: TOGNETTA, Luciene Regina Paulino (Org.). Virtudes e educação: o desafio da modernidade. v. 1. 1 ed. Campinas: Mercado de Letras, 2007. p. 147-157.

SOUZA, Vera Lúcia Trevisan de; PLACCO, Vera Maria Nigro de Souza. 0 autorrespeito na escola. Cadernos de Pesquisa, São Paulo, v. 38, n. 135, p. 729-755, 2008.

TAYLOR, Charles. Sources of the self: the making of the modern identity. Cambridge: Harvard University Press, 1989.

TESTONI, Raquel Jaqueline Freiberger; TONELLI, Maria Juracy Filgueiras. Permanências e rupturas: sentidos de gênero em mulheres chefes de família. Psicologia e Sociedade, Florianópolis, v. 18, n. 1, p. 40-48, jan./abr. 2006.

TOGNETTA, Luciene Regina Paulino. Sentimentos e virtudes: um estudo sobre a generosidade ligada às representações de si. São Paulo, 2006. 320 f. Tese (Doutorado em Psicologia Escolar e do Desenvolvimento Humano) - Instituto de Psicologia, Universidade de São Paulo, 2006.

TOGNETTA, Luciene Regina Paulino; ASSIS, Orly Zucatto Mantovani de. A construção da solidariedade na escola: as virtudes, a razão e a afetividade. Educação e Pesquisa, São Paulo, v. 32, n. 1, p. 49-66, jan./abr. 2006.

TUGENDHAT, Ernst. Lições sobre ética. Petrópolis: Vozes, 1996.

YIN, Robert K. Estudo de caso: planejamento e métodos. Porto Alegre: Bookman, 2005.

Recebido em: 22.09.2013

Aprovado em: 15.04 .2014

Nelson Pedro da Silva é mestre em psicologia da educação, doutor em psicologia do desenvolvimento humano, docente do curso de psicologia na Universidade Estadual Paulista (UNESP - Assis) e membro da Sociedade Brasileira Jean Piaget. 